\title{
LAS CONTRATACIONES DEL ESTADO EN LOS TIEMPOS DEL COVID-19
}

\section{THE CONTRACTING OF THE STATE IN THE TIMES OF COVID-19}

Diana Calixto Gabriel

* Abogada por la Universidad del Sagrado Corazón-Unife, especialista en temas de contrataciones públicas.

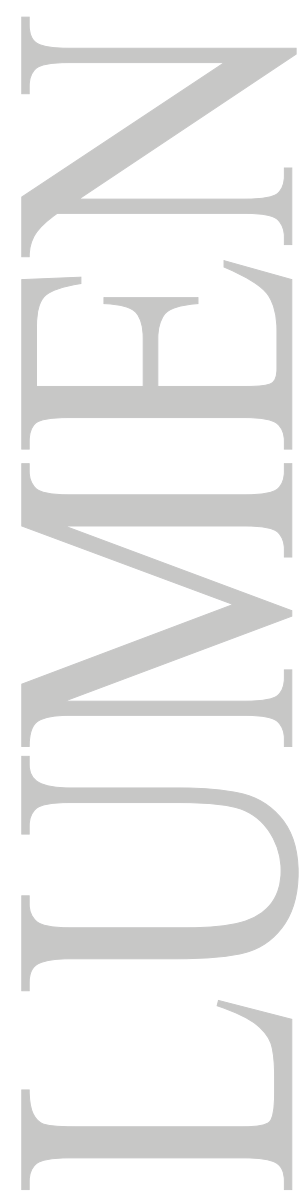




\title{
LAS CONTRATACIONES DEL ESTADO EN LOS TIEMPOS DEL COVID-19
}

\author{
THE CONTRACTING OF THE STATE IN THE TIMES OF COVID-19
}

Diana Calixto Gabriel

\begin{abstract}
RESUMEN
El presente artículo otorga una perspectiva de las compras públicas en el contexto de la situación que se vive por la pandemia ocasionada por el COVID-19, y de cómo el Estado a ponderado las compras necesarias dentro de un país que se encuentra en la lucha frontal ante un virus que llega a ser mortal. En tal sentido, desarrollaré esta investigación de acuerdo con la normativa actual de las Contrataciones del Estado.
\end{abstract}

En dicho contexto, el presente pretende reflexionar, desde una óptica jurídica, los principales desafíos que enfrenta el país y las tomas de decisiones que ha tomado el gobierno frente a la pandemia.

\section{PALABRAS CLAVE}

Ley de Contrataciones del Estado, Reglamento de la Ley de Contrataciones, licitaciones, contratación pública, pandemia, Coronavirus, COVID-19, Administración Pública, OSCE, Seace.

\section{ABSTRACT}

This article provides a perspective of public purchases in the context of the events within the Coronavirus pandemic, COVID-19, and how the State has weighted the necessary purchases within a country that is encountering against a virus that becomes fatal. In this sense, I will perform this investigation in accordance with the current regulations of the State Procurement.

In this context, hereby aims to reflect, from a legal perspective, the main challenges that is facing the country and the government's decision-making against the pandemic.

\section{KEY WORDS}

State Contracting Law, Regulation of the Contracting Law, Tenders, Public Contracting, pandemic, Coronavirus, COVID-19, Public Administration, OSCE, Seace.

\section{INTRODUCCIÓN}

Actualmente, venimos siendo testigos de las noticias emitidas tanto por los medios de comunicación nacionales como los internacionales, en las cuales se reporta un elevado número de infectados y fallecidos por la enfermedad del coronavirus (COVID-19) alrededor del mundo. Se presume que el primer caso se reportó en Wuhan (China) en el 2019, que luego fue confirmado y calificado en los primeros meses del presente año (el 11 de marzo del 2020) por la Organización Mundial de la Salud (OMS) como un brote infeccioso producido por el COVID-19, el cual se ha expandido rápidamente a nivel global y hoy la población de más de 100 países se ve afectada por este, entre ellas, la nuestra.

Por ello, ante el elevado riesgo que supone esta enfermedad, el presidente anunció la declaración del estado de emergencia en todo el territorio mediante el Decreto Supremo № $044-$ 2020-PCM, y las medidas a tomar mediante Decreto de Urgencia $N^{\circ} 026-2020$, en un periodo de 15 días calendarios que comenzó desde las 00:00 horas del 16 de marzo del 2020 para evitar que el virus se propagara. A pesar de las medidas adoptadas, se elevó el número de infectados y fallecidos, y por ello, se extendió la cuarentena hasta el 24 de mayo del 2020. 
Dentro de este contexto, el gobierno restringió la circulación de las personas en la vía pública y el cierre de fronteras, con el trabajo de la Policía Nacional del Perú y las Fuerzas Armadas. Además, se restringió la circulación de vehículos personales, el cierre de locales y la venta de bienes que no estuvieran incluidos dentro de los artículos de primera necesidad.

Se trata de una situación extraordinaria, sin precedentes, puesto que ha golpeado a la comunidad internacional y que ha puesto en jaque la economía mundial, afectando a gobiernos, inversores multimillonarios y a pequeñas empresas alrededor del mundo, quienes se han visto en la obligación de parar las actividades que les corresponde. Sin embargo, debido a que algunos países ya están "superando" la proliferación de la enfermedad, están disminuyendo las medidas de confinamiento y distanciamiento social obligatoria para que se empiece abrir las economías. Los Economistas de Goldman Sachs Group Inc. Y Morgan Stanley señalan, en un tono esperanzador, que la economía mundial está comenzando a recuperarse (Fuente: Noticia RT).

De otro lado, debemos tener presente que las medidas de restricción en nuestro país continúan y eso ha logrado que las entidades públicas tomen en cuenta lo decretado por el gobierno, a fin de que las contrataciones realizadas por el Estado prioricen el marco actual, esto forma parte de la gestión pública de nuestro país.

Por esta situación en este artículo se busca responder a las siguientes preguntas: ¿cómo está actuando el Estado en las contrataciones públicas frente al problema del coronavirus?, ¿qué se busca proteger?, ¿por qué se debe destinar el dinero a ciertos productos y servicios?

\section{CONTENIDO}

Las entidades públicas deben adquirir bienes, servicios y/o ejecución de obras públicas para alcanzar sus fines, y cumplir con sus objetivos y metas. Dado lo anterior, el Ministerio de Economía y Finanzas (MEF) se encarga de emitir anualmente un presupuesto y pliegos presupuestales para estas entidades, tanto a nivel nacional como a nivel regional y local. Ahora bien, el presupuesto destinado tiene en consideración el Plan Anual de Contrataciones (PAC) en el que se inscriben las necesidades en obras, bienes y servicios que estas entidades demandan para poder cumplir con sus respectivas funciones (Torres, 2012).

La regulación de las Contrataciones del Estado es de gran importancia en el ámbito jurídico, puesto que debido a ella las entidades estatales pueden efectuar las compras que beneficien de forma directa o indirecta a la ciudadanía y satisfacer las necesidades públicas. Todos los contratos suscritos son efectuados con fondos públicos, por ello se deben regir bajo los principios de la Ley de Contrataciones del Estado y su reglamento (en adelante denominada en este documento como la Ley), con el fin de usar y maximizar los recursos públicos.

A diferencia con los contratos en el ámbito privado en el que se puede de convenir la compra de bienes, servicios u obras con el objeto, modalidad, condiciones, monto y plazos acordados por las partes su regulación. En el ámbito público, aquellas entidades constituyen una parte del sistema de la Administración Pública, se encuentran sujetas a realizar el proceso de contratación bajo la norma de las Contrataciones del Estado y con la supervisión del Órgano Supervisor de la Contrataciones del Estado (OSCE).

El OSCE como organismo técnico especializado, supervisa los diferentes métodos de contratación pública que existen en la legislación peruana, entre ellas, la contratación directa.

Dentro de un contexto normal, las Contrataciones del Estado siguen la línea desarrollada en la normativa; sin embargo, la Ley ha previsto el desarrollo de las contrataciones estatales dentro 
de una situación de emergencia. En cuanto a ello "debemos tener en consideración que, dada la excepcionalidad de esta causal, las contrataciones que se realicen bajo su amparo deberán ser las estrictamente necesarias para salvar la emergencia de forma inmediata" (Paz, 2019, p.263

La Ley ha estipulado que cuando se presenta una situación de emergencia el Estado puede hacer una contratación de directa con determinado proveedor, dada la urgencia con la que deben enfrentarse este tipo de eventos. Entre ellos, la Ley 30225 del 2019, señala en su Art. 27 que estas pueden ser: emergencias sanitarias declaradas por el Ministerio de Salud, ente rector del sistema nacional de salud; otras ocasionadas por acontecimientos catastróficos para los habitantes del territorio; aquellas que representen un riesgo o generen algún tipo de afectación para la defensa y/o la seguridad nacional; u otras que puedan ocasionar las situaciones mencionadas.

Conforme a la coyuntura y de acuerdo con lo regulado en la norma, la pandemia del coronavirus justifica que el ente rector de salud de nuestro país declare el estado de emergencia sanitaria nacional. Por lo tanto, se habilita la causal de contratación directa y se faculta a todas las entidades del Estado a contratar de manera inmediata para atender los requerimientos generados por el COVID-19.

Como se mencionó en la introducción de este artículo, el 11 de marzo del 2020 el Gobierno Nacional declaró el estado de emergencia sanitaria en todo el territorio, días después (15 de marzo del 2020) la Presidencia del Consejo de Ministros (PCM) le informó a la comunidad el inicio de la emergencia en todo el país (Cabral, 2020). Posteriormente, la Dirección General de Abastecimiento, que está en línea del Ministerio de Economía y Finanza (MEF) y figura como el ente rector del Sistema Nacional de Abastecimiento (SNA), estableció una serie de disposiciones temporales para todas la entidades públicas, los usuarios y la ciudadanía del territorio nacional, declarando la suspensión de los cómputos de los términos establecidos para los procedimientos de selección; el perfeccionamiento de contratos, tanto los convocados como los celebrados; y otros regímenes de contratación pública del SNA (Ministerio de Economía y Finanzas, s.f.).

De igual manera, en el Art. 1 de la Resolución 001 del 2020 estableció que no se podrán convocar nuevos procedimientos de selección, ni los regímenes comprendidos por el SNA. Únicamente se podrán convocar los que estén relacionados con las disposiciones que se incluyeron en el Decreto Supremo $N^{\circ}$ 044-2020-PCM para prevenir que la enfermedad por el COVID-19 se propague aún más en el territorio.

De esa manera, el gobierno cumple con lo normado en la ley y destina el presupuesto que se podrá utilizar en las contrataciones directas. Es así como se espera que el gasto del erario se destine a lo siguiente: el equipamiento que necesitan los centros hospitalarios constituidos como tal y los provisionales para atender la emergencia, así como también el que requieren los lugares de alojamiento para las personas que han sido repatriadas o se vieron obligadas a desplazarse hacia el interior del país; asimismo, se espera que dentro del gasto se incluya la obtención de dispositivos electrónicos y servicios de internet; la adquisición de pruebas para COVID-19, mascarillas y demás elementos necesarios para enfrentar la emergencia ocasionada por el virus (Cabral, 2020). Todo ello sustentado en las resoluciones que ha emitido el gobierno.

\section{CONTRATACIÓN DIRECTA EN EL ESTADO DE EMERGENCIA}

Como ya señalamos anteriormente, la regulación establecida indica que, en situaciones excepcionales, se deben paralizar otros procesos de selección. Entre ellos se encuentran las licitaciones de carácter público, la contratación del servicio de consultor de personas naturales, las convocatorias para concursos públicos, los servicios de compras corporativas, los procedimientos de comparación de precios, el encargo, la adquisición de bienes por medio de subasta inversa electrónica, el método de adjudicación simplificada, y los procesos adicionales de contratación que 
fueron incluidos en el reglamento como Catálogos Electrónicos de Acuerdo Marco (Organización para la Cooperación y el Desarrollo Económicos [OCDE], 2017).

Estos están conformados por actos administrativos a través de los cuales se realizan los procedimientos de selección, tanto de las personas naturales como las jurídicas, para contratar obra, bienes, consultoría y/o servicios. Los términos que se estipulan para cada uno de esos actos administrativos varían de acuerdo con el objeto de la contratación y el valor referencial que tenga. Por ello son más complejos e incluyen un periodo de presentación, luego una fase en la que son absueltas las consultas y las observaciones realizadas, seguida de un proceso en el que estas se integran a las bases, después se evalúan y califican las ofertas económicas presentadas y se selecciona la persona o a los participantes a quienes se le otorgará la buena pro (Organismo Supervisor de las Contrataciones del Estado [OSCE], s.f.).

Por otra parte, cuando se presente una situación de emergencia, las entidades tienen la posibilidad de llevar a cabo un proceso de Contratación Directa con uno o más proveedores, para que estos le suministren los bienes, ejecuten las obras y/o realicen la prestación de los servicios que se requieren para prevenir las posibles consecuencias que se derivarían del evento en caso de que este ocurra, o bien para subsanarlas cuando ya ha acontecido (Portal Municipio al Día, s.f.). En estos casos, se ha estipulado que el término máximo para regularizarlo son 10 día hábiles después de que se produjo la entrega de la obra, bien o servicio por parte del proveedor.

Según Paz (2019) las denominadas "contrataciones directas" son los supuestos equivalentes que anteriormente se denominaba causales de "exoneración". En esencia se trata del mismo mecanismo con una nueva denominación, tal es así que, ya sea en la exoneración o en la contratación directa, la finalidad es la vinculación de un determinado proveedor con la entidad, sin usar los mecanismos de selección convencionales.

Por lo que podemos concluir que las contrataciones directas se tratan de la excepción a la regla, aunque siguen las formalidades de la Ley y su Reglamento, no realiza todas las etapas de las distintas modalidades en los procedimientos de selección.

\section{DERECHO A LA SALUD Y LAS COMPRAS ESTATALES}

La pandemia del coronavirus afecta a muchos peruanos, por ello se busca proteger, en primera instancia, los derechos que se encuentran en riesgo como el derecho a la salud. Esta ha sido definida por la OMS (s.f.) como aquel estado en el que se encuentran las personas que sienten bienestar físico, y a la vez experimentan esta sensación tanto mental como socialmente, es decir, la salud es un estado de bienestar general que abarca muchos ámbitos de la persona.

La salud es tan esencial que ha sido consagrada en la Constitución peruana como un derecho para todas las personas que, a su vez, debe ser protegido y promocionado tanto en el medio familiar como a nivel comunitario. Asimismo, en el artículo 7 de la Carta se señala que también tienen derecho a ser respetados en su dignidad aquellas personas que por causa de alguna deficiencia de tipo física o metal no puedan velar por la protección de este derecho y, por lo tanto, debe cobijarlos un régimen legal de protección, atención, readaptación y seguridad (Congreso Constituyente Democrático, 1993).

Para garantizar el derecho fundamental a la salud en todo el territorio nacional el Estado creó una Política nacional de salud que debe ser normada y supervisada por el Poder Ejecutivo, a fin de lograr la descentralización y el acceso de todos al servicio de salud por parte de todos los ciudadanos, como se establece en el artículo 44 constitucional: el Estado tiene la obligación de ser garante de la vigencia de los derechos humanos. 
En el Título Preliminar de la Ley N ${ }^{a}$ 26842, también conocida como Ley General de Salud, específicamente en los artículos II y VI, se determina que la salud de debe ser protegida por toda la comunidad en general, además de ser considerado un bien común que el Estado debe regular, vigilar y promover. A su vez, por ser garante de los derechos de los habitantes del territorio, a este le corresponde garantizar la cobertura oportuna, segura y con calidad de las prestaciones de salud y provisionar los servicios de salud pública observando el principio de equidad. Cabe anotar que entre las disposiciones constitucionales se incluye la observación de que este es un deber irrenunciable del Estado peruano. En conclusión, se debe garantizar que se brinde la seguridad de la salud con un conjunto de condiciones mínimas que permitan la realización del ser humano frente al posible riesgo de su derecho.

Acorde a ello el Ministerio de Salud aprobó el "Plan Nacional de Preparación y Respuesta frente al riesgo de introducción del coronavirus 2019 - nCoV". Por medio de este se busca tomar las acciones necesarias para reducir el impacto que puede producir el COVID-19 en la salud de las personas, en la sociedad peruana y en la economía nacional, y ante los riesgos que representa la pandemia.

Por tanto, es prioridad en estos casos es que el Estado destine el presupuesto del erario para la compra de productos que tengan como finalidad proteger la salud tanto de sus ciudadanos como la de aquellas personas que se encuentran en el territorio nacional. Hasta el momento los productos que se requieren son las mascarillas, textiles y pruebas para COVID-19; el equipamiento de establecimientos hospitalarios provisionales para atender la emergencia, y de alojamiento para repatriados y desplazados; así como la compra de servicios de internet y dispositivos electrónicos (Cabral, 2020).

\section{ALERTA DE CORRUPCIÓN EN LAS COMPRAS DIRECTAS}

A pesar de que el OSCE mediante su portal Conosce, plataforma en la que se pretende brindar a todos los ciudadanos información sobre las contrataciones para la provisión de bienes y prestación de servicios que las entidades públicas requieren en una situación de emergencia. Las noticias demuestran que ha habido irregularidades en algunas compras como el de sobrevaloración del precio. Como ejemplo tenemos que la Primera Fiscalía Especializada en Delitos de Corrupción de Funcionarios de Lima Centro inició una investigación con el objetivo de identificar la responsabilidad penal que tiene la cotización sobrevalorada de los elementos de bioseguridad que actualmente se requieren para evitar la propagación del COVID-19 en el territorio (Álvarez, 2020). Por otro lado, vemos que la Contraloría General de la República se ha visto en la necesidad de suspender los procesos de adquisición que su dependencia ha venido requiriendo, esto con la finalidad de ser puesta a disposición de la Fiscalía y Auditoría Interna.

Nuestro país viene pasando por un proceso de la lucha frente a la corrupción, que es un mal enquistado en nuestras entidades públicas, pero que no es ajeno a lo que sucede en otros países que forman parte de la región de América Latina y el Caribe, como lo indicó Rose Ackerman. Pues la corrupción en este sector es una problemática generalizada que se presenta en todos los países, sin embargo, se ha evidenciado que en algunos territorios está práctica está más extendida y genera mayores costos para las naciones por la proporción que tienen los negocios públicos (Rose Ackerman, 2004). Por ello es considerado un problema institucional que requiere ser cambiado con profundas reformas.

De acuerdo con lo señalado por Jareño (2017) "La modalidad de Contratación Directa es una de las fuentes más frecuentes del a Contratación delictiva" (p. 3). En la práctica, vemos como estas conductas corruptas abren camino a una sanción administrativa que puedes ser seguido de la jurisdicción penal como ultima ratio, en la que se encuentran tipificadas distintos delitos para funcionarios públicos involucrados en actos de corrupción. 
Dentro del ámbito legal de la Contratación Pública, la corrupción genera un costo económico y social en la que se ve afectado el interés público, dado que se adquieren bienes o se obtiene la prestación de uno más servicios por un precio más elevado y de menor calidad, lo que le abre paso a la discrecionalidad.

\section{CONCLUSIONES}

En medio de una situación de emergencia como la que vivimos actualmente, esta eventualidad se ha previsto, en la Ley de Contrataciones del Estado, como una causal para la contratación directa. Por lo que se puede inferir como una situación de excepción que debe ser aplicada de manera restrictiva previo cumpliendo con las disposiciones y los requerimientos que se estipularon tanto en la LCE como en su reglamento. Este uno de los procesos más inmediatos que se realiza cuando se requiere el suministro o la prestación y ejecución de bienes, servicios y obras, respectivamente.

Asimismo, en la normativa de Contrataciones del Estado se indica que las situaciones de emergencia son: aquellos hechos catastróficos, situaciones o eventos que pueden ocasionar una afectación o representan un riesgo para la defensa o la seguridad nacional, políticas con las cuales se busca enfrentar o dirimir los conflictos o agresiones internas y externas que perjudican u obstaculizan la consecución de los fines del Estado (Portal Pasión por el Derecho, 2020), o también aquellas las situaciones que suponen un grave peligro para la población en general y las emergencias sanitarias.

En los casos donde se presenta un evento que ocasiona una situación de emergencia, como régimen de excepción, el Estado ha seguido lo estipulado en nuestra Carta Magna y se ha ponderado la compra de suministros que protejan la salud de los ciudadanos. La información de aquellas compras se puso a disposición de los ciudadanos a través del portal de la OSCE.

Podemos observar que uno de los derechos más vulnerables en nuestro país y en todo el mundo es el derecho a la salud, y que se pretende proteger mediante las políticas nacionales y la gestión pública, a fin de que la pandemia por el coronavirus no afecte a más personas en el territorio nacional. Pese a ello las noticias actuales demuestran que hay irregularidades en el uso del gasto público, sobrevaloración en las compras y otros actos que llegarán a ser puestos a disposición de investigación.

De ser el caso, se pondrá en evidencia la fragilidad de nuestro sistema de abastecimiento y el vacío legal que tienen los procesos de contrataciones estatales. Ello permite que un proceso de selección tan necesario por su inmediatez se convierta en un arma de corrupción, y en una afectación para el derecho que tiene toda persona a la salud, por ser fundamental e inherente a todos los seres humanos.

\section{REFERENCIAS}

- Álvarez, M. (2020). Fiscalía realizó diligencia en sede de la Contraloría por adquisición de mascarillas y alcohol. Obtenido de Periódico El Comercio: https://elcomercio.pe/politica/ coronavirus-fiscalia-abre- investigacion-y-realiza-diligencia-en-local-de-la-contraloria-porcaso-de-presuntas-compras- irregulares-noticia/

- Andía, W. (2004). El sistema nacional de inversión pública. Un análisis crítico. Revista Industrial Data. 7.

- Aymerich, C. (2014). Corrupción y contratación pública análisis de las nuevas directivas europeas de contratos y concesiones públicas. Revista Aragonesa de Administración Pública. (45-46), 209-236. 
- Cabral, E. (2020). Perú destina más de S/442 millones en compras sin competencia para COVID-19. Obtenido de Ojo Público: https://ojo-publico.com/1805/covid-19-peru-destinamillones-para-compras- sin-competencia

- Congreso Constituyente Democrático. (1993). Constitución Política del Perú. Lima: Congreso Constituyente Democrático.

- Congreso de la República. (1997). Ley N² 26842 de 1997. (Ley General de Salud). Lima, Perú.

- Congreso de la República. (2019). Ley N 30225 del 13 de marzo de 2019. (Ley de Contrataciones del Estado). Lima, Perú.

- Jareño, Á. (2017). Conductas delictivas en materia de contratación pública. Revista Internacional Transparencia e Integridad. (5), 1-6.

- Meza, Y. (2019). Comentarios al T.U.O de la Ley de Contrataciones del Estado. Lima: Juristas Editores E.I.R.L.

- Ministerio de Economía y Finanzas. (2020). Resolución Directoral Nº 001 del 16 de marzo de 2020. (Suspensión de plazos de procedimientos de selección en materia de abastecimiento). Lima, Perú.

- Ministerio de Economía y Finanzas. (s.f.). Dirección General de Abastecimiento. Obtenido de Portal mef: https://www.mef.gob.pe/es/quienes-somos/organizacion/ organos-de-linea/308-acerca-del- ministerio/organos-de-linea/6183-direccion-general-deabastecimiento

- Ministerio de Educación. (2020). Plan nacional de preparación y respuesta frente al riesgo de introducción del coronavirus 2019-nCoV. Lima: Ministerio de Educación.

- Naser, A., y Concha, G. (2011). El gobierno electrónico en la gestión pública. Santiago de Chile: Organización de las Naciones Unidas [ONU].

- Organismo Supervisor de las Contrataciones del Estado [OSCE]. (s.f.). Proceso de Selección: Procedimiento Clásico. Lima: Organismo Supervisor de las Contrataciones del Estado [OSCE].

- Organización Mundial de la Salud [OMS]. (s.f.). ¿Cómo define la OMS la salud? Obtenido de Portal Who: https://www.who.int/es/about/who-we-are/frequently-asked-questions

- Organización para la Cooperación y el Desarrollo Económicos [OCDE]. (2017). La contratación pública en el Perú. París: Organización para la Cooperación y el Desarrollo Económicos [OCDE].

- Portal Municipio al Día. (s.f.). Contratación directa por situación de emergencia. Obtenido de Portal Municipio al Día: https://municipioaldia.com/consejos-del-mes/contrataciondirecta-por-situacion-de- emergencia/

- Portal Pasión por el Derecho . (2020). Guía «Contratación directa bajo situación de emergencia». Obtenido de Administrativo: https://lpderecho.pe/guia-orientacioncontratacion-directa-bajo-situacion- de-emergencia/

- Presidencia de la República. (2020). Decreto de Urgencia № 026 del 15 de marzo de 2020. (Decreto de urgencia que establece diversas medidas excepcionales y temporales para prevenir la propagación del coronavirus (COVID-19) en el territorio nacional). Lima, Perú.

- Presidencia del Consejo de Ministros. (2020). Decreto Supremo № 044 del 15 de marzo de 2020. (Decreto Supremo que declara Estado de Emergencia Nacional por las graves circunstancias que afectan la vida de la Nación a consecuencia del brote del COVID-19). Lima, Perú.

- Torres, D. (2012). Delitos de corrupción en las contrataciones con el Estado: algunos aspectos a tomar en cuenta. Lima: Comentario académico IDEHPUCP.

- Volosin, N. (2015). Datos abiertos, corrupción y compras públicas. Iniciativa Latinoamericana por los Datos Abiertos.

Fecha de recepción: 22 de mayo de 2020

Fecha de aceptación: 01 de junio de 2020 